\title{
The Efficiency Comparative Evaluation of Logistics-IT Companies Using the Data Envelopment Analysis Approach
}

\author{
JaeHyun Kim \\ Dept. of Computer Engineering, Seokyeong University \\ 16-1 Jungneung-Dong, Sungbuk-Ku, Seoul 136-704, KOREA \\ statsr@skuniv.ac.kr
}

\begin{abstract}
Development in the logistics industry has led Logistics-IT's advancement. However, due to stagnating global economy, logistics industry and Logistics-IT have experienced difficulties.

As a result, Logistics-IT companies seek ways to strengthen competitive advantage in order to respond to external environment. The resolution is to increase efficiency. However, increased efficiency of management involves measurement of the efficiency of input factor and output factor and through this measurement, inefficiency would be handled with.

This study selects multi-input factor and multi-output factor and evaluates the technical efficiency (TE) and pure technical efficiency (PTE) to analyze the cause of inefficiency. In addition, it shows that inefficient companies benchmark efficient ones to set target value and conducts analysis of Scale Efficiency (SE) and Return to Scale (RTS). We have also conducted analysis of super efficiency to classify the ranking between the efficient companies.

Through our study, we anticipate companies to improve and become efficient through comparative evaluation and benchmarking by setting target value.

Keywords: comparative efficiency, Data Envelopment Analysis (DEA), decision making unit (DMU), technical efficiency (TE), pure technical efficiency (PTE), Scale Efficiency (SE), Return to Scale (RTS)

\section{Introduction}

Korea's trade structure composes of importing raw materials and exporting the tollprocessed goods due to lack of natural resources. Its economy focuses on exporting goods rather than domestic market. As a result of these characteristics of trade and structure of the economy, logistics industry has developed to handle quantity of goods transported. Therefore, logistics industry is affected enormously by domestic economic growth and the global economy. Domestic economy has experienced low economic growth for several years.

The economic growth and conditions of other countries impacts performance of logistics industry in Korea. For example, China, which is one of our major trading partners, has experienced slowing economic growth decreasing trade volumes causing difficulties in logistics industry. Unfortunately, slowing economic growth in China is expected to continue for several years making it even harder to recover.

However, Korea's logistic industry is improving on technical productivity to address the issue. The introduction of IT techniques improves productivity through increasing proportion of 3PL (Third Party Logistics) and 4PL (Fourth party Logistics) [10]
\end{abstract}

Received (July 16, 2017), Review Result (September 29, 2017), Accepted (October 14, 2017) 
The form of logistics is divided by the relationship between shipper company and logistics company. 1PL is when shipper company does logistics business utilizing its own labor, equipment and facilities, in addition 2PL refers to outsourcing its business to subsidiary company, whereas, 3PL is when logistics company outsources business to those who are in third party relationship. 4PL is a concept expanded from 3PL which logistics company affiliates with shipper company on IT and consulting to provide integrated solutions [10].

IT techniques are applied to logistics functions. For example, storage function, an IT solution called WMS (Warehouse Management System) is used which is a software application designed to support warehouse or distribution center management and staff, and for transportation function, TMS (Transportation Management System) is used which is a subset of supply chain management concerning transportation operations and it may be part of an enterprise resource planning system. For order function, OMS (Order Management System) is used.

Moreover, government provides assistance on the establishment of Smart logistics systems through the combination of traditional logistics industry and advanced IT technology. In order to increase efficiency in logistics industry, the establishment of logistic system is essential and IT is the key factor for combination of the two. However, there is inherent limitation for logistics companies to establish their own logistics systems which leads them to seek assistance from IT companies.

Logistics-IT company is defined as those companies providing IT related solution, systems, equipment, education and consulting to logistics companies, shipper companies and ordinary companies [10].

The transition of logistics industry with Logistics-IT companies is effective however; efficiency is still an important issue to be successful.

In this study a comparison of the efficiency of Logistics-IT companies and solutions for inefficient companies to improve efficiency through a benchmarking is provided. We utilized Data Envelopment Analysis (DEA) throughout the study, which is a widely used multi-criteria decision making method.

\section{Methodology}

\subsection{DEA Model [1]}

DEA is a mathematical model that measures the relative efficiency of DMUs with multiple inputs and outputs but with no obvious production function to aggregate the data in its entirety. Relative efficiency is defined as the ratio of total weighted output to total weighted input. By comparing $\mathrm{n}$ units with s outputs denoted by $y_{r k}, r=1,2, \ldots, s$, and $\mathrm{m}$ inputs denoted by $x_{i k}, i=1,2, \ldots, m$, the efficiency measure for DMU $k$ is

$$
h_{k}=\max \frac{\sum_{r=1}^{s} u_{r} y_{r k}}{\sum_{i=1}^{m} v_{i} x_{i k}}
$$

s. t.

$$
\begin{aligned}
& \frac{\sum_{r=1}^{S} u_{r} y_{r j}}{\sum_{i=1}^{m} v_{i} x_{i j}} \leq 1, \text { for } j=1, \ldots, n \\
& u_{r} \geq 0, \text { for } r=1, \ldots, s \\
& v_{i} \geq 0, \text { for } i=1, \ldots, m
\end{aligned}
$$

Where, $u_{r k}$ and $v_{i k}$ are weights. $h_{k}$ is the efficiency score, and is less than and equal to 1 . 
The result of the DEA is the determination of the hyperplanes that define an envelope surface or Pareto frontier. DMUs that lie on the surface determine the envelope and are deemed efficient, whilst those that do not are deemed inefficient. The formulation described above can be translated into a linear program, which can be solved relatively easily and a complete DEA solves $n$ linear programs, one for each DMU.

$$
h_{k}=\max \quad \sum_{r=1}^{s} u_{r} y_{r k}
$$

s.t.

$$
\begin{aligned}
& \sum_{i=0}^{m} v_{i} x_{i j}-\sum_{r=1}^{s} u_{r} y_{r j} \geq 0 \text { for } j=1, \ldots, n \\
& \sum_{i=1}^{m} v_{i} x_{i k}=1 \\
& u_{r} \geq 0, \text { for } r=1, \ldots, s \\
& v_{i} \geq 0, \text { for } i=1, \ldots, m
\end{aligned}
$$

Formula (2) often referred to as the CCR model (Charnes et al., 1978), assumes that the production function exhibits constant returns-to-scale.

The BCC(Banker et al., 1984) model adds an additional constant variable, $c_{k}$, in order to permit variable returns-to-scale:

$$
h_{k}=\max \quad \sum_{r=1}^{S} u_{r} y_{r k}+c_{k}
$$

s. t.

$$
\begin{aligned}
& \sum_{i=0}^{m} v_{i} x_{i j}-\sum_{r=1}^{s} u_{r} y_{r j}-c_{k} \geq 0 \text { for } j=1, \ldots, n \\
& \sum_{i=1}^{m} v_{i} x_{i k}=1 \\
& u_{r} \geq 0, \text { for } r=1, \ldots, s \\
& v_{i} \geq 0, \text { for } i=1, \ldots, m
\end{aligned}
$$

It should be noted that the results of the CCR input-minimized or output-maximized formulations are the same, which is not the case in the BCC model. Thus, in the outputoriented BCC model, the formulation maximizes the outputs given the inputs and vice versa.

\subsection{Procedure of DEA}

In this section explains how to use the DEA. It is a tool for evaluating the DMU. The method consists of five steps, and is briefly described below. The overall flow is shown in Figure 1.

\subsubsection{Data Collection}

The Potential factors (e.g., employee, assets, sales etc.) of the company to be analyzed have to be collected and recorded. The quality of the collected data is very important because it determines the quality of the decision. 


\subsubsection{Factor Selection}

The main factors have a direct impact on decision making. So the number of factors must be limited and this has a significant influence on decision making.

\subsubsection{Selection of DEA Model}

After selecting appropriate factors, the most relevant model for DEA analysis should also be selected. DEA model is selected considering the calculation of the projection, the DMU characteristics and the characteristics of the factors.

\subsubsection{Implementation of the DEA Model}

After selection of the DEA model, using the software package to the DEA execution. In this paper, we use the DEA-solver.

\subsubsection{Result Analysis}

After implementing DEA, the conclusion drawn from it can be used to analyze efficiency ranking, projection and super efficiency.

\begin{tabular}{|c|c|c|}
\hline STEP 1 & Data collection & $\begin{array}{l}\text { - Collect detailed company } \\
\text { information }\end{array}$ \\
\hline STEP 2 & Factor selection & - Choose input/output factors \\
\hline STEP 3 & Model selection & $\begin{array}{l}\text { - Select proper DEA model } \\
\text { as approach }\end{array}$ \\
\hline STEP 4 & $\begin{array}{l}\text { Run the DEA model with } \\
\text { specific ranking method }\end{array}$ & $\begin{array}{ll}\text { - } & \text { Choose DEA software } \\
\text { - } & \text { Choose DEA a ranking }\end{array}$ \\
\hline STEP 5 & Result Analysis & $\begin{array}{l}\text { Analyze the result to assist } \\
\text { in decision making }\end{array}$ \\
\hline
\end{tabular}

\section{Figure 1. Procedure of DEA[7]}

\section{Analysis of Efficiency}

In this part, the 5 steps demonstrated in Figure. 1 has been applied to evaluate efficiency of Logistics-IT companies.

\subsection{Data Collection and Factor Selection}

In this section, we have selected Logistics-IT companies as those listed IT companies that sales results are focused on logistics industry. As a result, 13 companies have been selected and they are the subject of the analysis. They are referred to as DMU.

In a DEA model, the selections of input and output factors are extremely important and to be valid, constant correlation is necessary between the factors.

Table 1 demonstrates correlation between input factors and output factors. In this study, 2 of the input factors and 3 of the output factors are selected. As shown in Table 1, correlation exists between the two factors and output factors are affected by the input factors. Therefore, the selection of the factors is valid. 
Table 1. Correlation Between Input Factors and Output Factors

\begin{tabular}{c|c|c|c|c|c}
\hline & Asset & Liabilites & Sales & Operating profit & Net profit \\
\hline Asset & 1 & $0.638(* *)$ & $0.635(* *)$ & $0.967(* *)$ & $0.853(* *)$ \\
\hline Liabilities & & 1 & $0.926(* *)$ & $0.452(* *)$ & $0.189(* *)$ \\
\hline Sales & & & 1 & $0.479(* *)$ & $0.261(* *)$ \\
\hline $\begin{array}{c}\text { Operating } \\
\text { profit }\end{array}$ & & & & 1 & $0.959(* *)$ \\
\hline Net profit & & & & & 1 \\
\hline
\end{tabular}

**Correlation is significant at the 0.01 level (2-tailed)

An asset is one of the input factors and it is referred to as a resource that is controlled by an entity as a result of past events and which generates future economic benefits to the enterprise.

Liability is another input factor and it is an obligation to make to another enterprise as a result of past events. It is a negative future economic benefit. It is a key element that it equals to an asset when combined with stockholders' equity.

In the meanwhile, sales are an output factor which is an activity of selling the amount of goods or services in a given time period is key to the growth of an enterprise.

Operating profit equals to revenue earned from the core operations of a business excluding any financing or tax-related expenses. It is an important element when evaluating the performance of an enterprise.

Net profit is another output factor and it represents the sales revenue remaining after deduction of operating expenses, interest, taxes and preferred stock dividends. It also represents an important element in a performance of an enterprise.

In the meanwhile, it is important to select an appropriate numbers of DMU and factors in the DEA model because the results of efficiency analysis may lead to a wrong conclusion if the numbers and factors selection is inappropriate. If the number of input and output factors are excessively large compared to DMU, the ability to distinguish between efficient and inefficient DMU is diminished, causing the results to be less reliable.

There are studies conducted on the selection of input and output factors to avoid excessive measure of efficiency in application of DEA model. Fitzsimmons (1994) suggests a standard as when selecting the numbers of input and output factor compared to DMU as $n>2(m+s)$. m represents the number of input factor and $s$ refers to the number of output factors and $\mathrm{n}$ is the number of DMUs to be analyzed. Thus, the factors in our study can be said to be appropriate.

Finally collecting data is shown Table 2.

Table 2. Collected Final Data

(unit: one hundred million won)

\begin{tabular}{r|r|r|r|r|r}
\hline DMU & \multicolumn{1}{|c|}{ Capital } & Liabilities & \multicolumn{1}{c}{ Sales } & $\begin{array}{c}\text { Operation } \\
\text { profit }\end{array}$ & Net profit \\
\hline D01 & 570,438 & 508,862 & 717,410 & 28,399 & 1,419 \\
\hline D02 & $4,214,025$ & $1,332,021$ & $7,897,748$ & 593,419 & 434,273 \\
\hline D03 & 93,668 & 59,455 & 235,040 & 14,361 & 8,765 \\
\hline D04 & 13,665 & 31,519 & 99,116 & 2,034 & 1,807 \\
\hline D05 & 47,353 & 59,490 & 114,130 & 5,447 & 3,305 \\
\hline D06 & 28,666 & 8,131 & 35,666 & 2,635 & 2,628 \\
\hline D07 & 232,179 & 475,507 & $1,084,167$ & 53,023 & 39,693 \\
\hline D08 & 28,625 & 119,814 & 142,056 & $-6,293$ & $-9,297$ \\
\hline
\end{tabular}




\begin{tabular}{c|r|r|r|r|r}
\hline D09 & 193,646 & 379,386 & 421,262 & 41,381 & 26,614 \\
\hline D10 & 824,990 & $1,411,102$ & $3,317,560$ & 153,372 & 79,952 \\
\hline D11 & 993,461 & $1,300,895$ & $2,293,984$ & 157,570 & 105,146 \\
\hline D12 & $2,518,243$ & $5,986,466$ & $22,408,068$ & 201,342 & 31,618 \\
\hline D13 & $2,602,367$ & $2,704,672$ & $2,425,967$ & 271,542 & 129,898 \\
\hline Max & $4,214,025$ & $5,986,466$ & $22,408,068$ & 593,419 & 434,273 \\
\hline Min & 13,665 & 8,131 & 35,666 & $-6,293$ & $-9,297$ \\
\hline Average & 950,871 & $1,105,948$ & $3,168,629$ & 116,787 & 65,832 \\
\hline SD & $1,277,469$ & $1,601,964$ & $5,936,162$ & 162,452 & 114,369 \\
\hline
\end{tabular}

\subsection{Efficiency Analysis}

Our goal in selecting a model of comparative efficiency analysis is to maximize multioutput therefore, we have chosen the output-oriented CCR and the output-oriented BCC model.

\subsubsection{CCR-O Model}

DEA presents a 'reference set' which is some of DMUs evaluated as efficient, assists the inefficient DMUs to benchmark the efficient DMUs. Through the 'reference set', inefficient DMUs are able to set target value to become efficient. It is because, as the 'reference set' is a model which inefficient DMUs can refer to as, and both referred DMUs and referring DMUs consist of groups of homogeneity in the input and output structures. Among the 'reference set' the DMUs with higher weight $\lambda$ can be concluded that input and output structures to have higher similarity

The average of efficiency score is 0.8349 and has a maximum score of 1 and minimum score of 0.3574 and standard deviation of 0.2202 .

Reference count for D02 is 6 times, 4 times for D03, 3 times for D04, 6 times for D07 and three times for D12. Reference count of D02 and D07 is relatively very high. Reference count is referred to as the number used for different evaluations of DMU analysis, which implies that the higher the value is, the more often it is used for the other evaluations of DMU analysis.

To give an example of the relationship between DMUs that are evaluated as inefficient and the reference set, for improved efficiency of D01, the reference of D02, D03, D12 is necessary. The efficiency of D01 is $35.74 \%$ compared to $100 \%$ for the other three. Therefore, among the efficient DMUs, D03 should be a target of benchmarking as it has the highest weighted value. Other inefficient DMUs should apply the same method.

DEA presents a target value for inefficient DMUs to become an efficient one. This allows for improvement in the efficiency of inefficient DMUs more easily to be efficient by suggesting the target value of what, how, and how much to be improved. It can be calculated using the efficiency ranking, the reference set, and weight $\lambda$ in Table 3.

Table 3. Summary of Outcomes for CCR-O Model

\begin{tabular}{c|c|c||c|c|c|c|c|c||c}
\hline DMU & Score & \multicolumn{1}{|c||}{ Rank } & \multicolumn{5}{c||}{ Reference(Lambda) } & \# of reference \\
\hline \hline D01 & 0.3574 & 13 & D02 & 0.017 & D03 & 4.301 & D12 & 0.039 & 0 \\
\hline D02 & 1 & 1 & D02 & 1 & & & & & 6 \\
\hline D03 & 1 & 1 & D03 & 1 & & & & & 4 \\
\hline D04 & 1 & 1 & D04 & 1 & & & & & 3 \\
\hline D05 & 0.6524 & 10 & D03 & 0.293 & D04 & 0.372 & D07 & 0.064 & 0 \\
\hline
\end{tabular}




\begin{tabular}{|c|c|c|c|c|c|c|c|c|c|}
\hline D06 & 0.9914 & 6 & D02 & 0.006 & & & & & 0 \\
\hline D07 & 1 & 1 & D07 & 1 & & & & & 6 \\
\hline D08 & 0.5577 & 12 & D12 & 0.011 & & & & & 0 \\
\hline D09 & 0.9545 & 7 & D02 & 0.002 & D07 & 0.791 & & & 0 \\
\hline D10 & 0.9221 & 8 & D03 & 2.256 & D04 & 5.721 & D07 & 2.306 & 0 \\
\hline D11 & 0.8302 & 9 & D02 & 0.101 & D07 & 2.454 & & & 0 \\
\hline D12 & 1 & 1 & D12 & 1 & & & & & 3 \\
\hline D13 & 0.5883 & 11 & D02 & 0.36 & D07 & 4.68 & & & 0 \\
\hline
\end{tabular}

DEA calculates a target value in order to improve inefficient DMUs by comparing with efficient DMUs. This target value is referred to as Projection and it is shown in Table 4 and Table 5. Projection is calculated as $\sum$ (referred actual value of DMUs) x (weighted value $(\lambda)$ of referred DMUs).

Therefore, in order for D01 to be an efficient DMU, assets and liabilities (input factors) remains the same while output factors for example, sales and operating profit each has to be increased by $179.8 \%(2,007,134$ hundred million won and 79,453 hundred million won, respectively) and net profit also should increase 3,154.3\% (46,178.2 hundred million won).

Table 4. Projection of CCR-O model's Input Factors

\begin{tabular}{l|r||r|r|r|r|r|c}
\hline \multirow{2}{*}{ DMU } & \multirow{2}{*}{ Score } & Data & Projection & $\begin{array}{c}\text { Diff. } \\
(\%)\end{array}$ & \multicolumn{1}{c|}{ Data } & Projection & $\begin{array}{c}\text { Diff. } \\
(\%)\end{array}$ \\
\cline { 3 - 8 } D01 & 0.3574 & 570,438 & 570,438 & 0.0 & 508,862 & 508,862 & 0.0 \\
\hline \hline D02 & 1 & $4,214,025$ & $4,214,025$ & 0.0 & $1,332,021$ & $1,332,021$ & 0.0 \\
\hline D03 & 1 & 93,668 & 93,668 & 0.0 & 59,455 & 59,455 & 0.0 \\
\hline D04 & 1 & 13,665 & 13,665 & 0.0 & 31,519 & 31,519 & 0.0 \\
\hline D05 & 0.6524 & 47,353 & 47,353 & 0.0 & 59,490 & 59,490 & 0.0 \\
\hline D06 & 0.9914 & 28,666 & 25,723 & -10.3 & 8,131 & 8,131 & 0.0 \\
\hline D07 & 1 & 232,179 & 232,179 & 0.0 & 475,507 & 475,507 & 0.0 \\
\hline D08 & 0.5577 & 28,625 & 28,625 & 0.0 & 119,814 & 68,048 & -43.2 \\
\hline D09 & 0.9545 & 193,646 & 193,646 & 0.0 & 379,386 & 379,386 & 0.0 \\
\hline D10 & 0.9221 & 824,990 & 824,990 & 0.0 & $1,411,102$ & $1,411,102$ & 0.0 \\
\hline D11 & 0.8302 & 993,461 & 993,461 & 0.0 & $1,300,895$ & $1,300,895$ & 0.0 \\
\hline D12 & 1 & $2,518,243$ & $2,518,243$ & 0.0 & $5,986,466$ & $5,986,466$ & 0.0 \\
\hline D13 & 0.5883 & $2,602,367$ & $2,602,367$ & 0.0 & $2,704,672$ & $2,704,672$ & 0.0 \\
\hline
\end{tabular}


Table 5. Projection of CCR-O model's Output Factors

\begin{tabular}{|c|c|c|c|c|c|c|c|c|c|c|}
\hline \multirow[b]{2}{*}{ DMU } & \multirow[b]{2}{*}{ Score } & \multicolumn{3}{|c|}{ Sales } & \multicolumn{3}{|c|}{ Operation profit } & \multicolumn{3}{|c|}{ Net profit } \\
\hline & & Data & Projection & $\begin{array}{l}\text { Diff. } \\
(\%)\end{array}$ & Data & Projection & $\begin{array}{l}\text { Diff. } \\
(\%)\end{array}$ & Data & Projection & $\begin{array}{l}\text { Diff. } \\
(\%)\end{array}$ \\
\hline D01 & 0.3574 & 717,410 & $2,007,134$ & 179.8 & 28,399 & 79,453 & 179.8 & $1,419.0$ & $46,178.2$ & $3,154.3$ \\
\hline D02 & 1 & $7,897,748$ & $7,897,748$ & 0.0 & 593,419 & 593,419 & 0.0 & $434,273.0$ & $434,273.0$ & 0.0 \\
\hline D03 & 1 & 235,040 & 235,040 & 0.0 & 14,361 & 14,361 & 0.0 & $8,765.0$ & $8,765.0$ & 0.0 \\
\hline D04 & 1 & 99,116 & 99,116 & 0.0 & 2,034 & 2,034 & 0.0 & $1,807.0$ & $1,807.0$ & 0.0 \\
\hline D05 & 0.6524 & 114,130 & 174,937 & 53.3 & 5,447 & 8,349 & 53.3 & $3,305.0$ & $5,773.9$ & 74.7 \\
\hline D06 & 0.9914 & 35,666 & 48,210 & 35.2 & 2,635 & 3,622 & 37.5 & $2,628.0$ & $2,650.9$ & 0.9 \\
\hline D07 & 1 & $1,084,167$ & $1,084,167$ & 0.0 & 53,023 & 53,023 & 0.0 & $39,693.0$ & $39,693.0$ & 0.0 \\
\hline D08 & 0.5577 & 142,056 & 254,714 & 79.3 & $-6,293$ & - 9,006 & 43.1 & - 9,297.0 & $-16,318.4$ & 75.5 \\
\hline D09 & 0.9545 & 421,262 & 876,467 & 108.1 & 41,381 & 43,353 & 4.8 & $26,614.0$ & $32,430.9$ & 21.9 \\
\hline D10 & 0.9221 & $3,317,560$ & $3,597,725$ & 8.4 & 153,372 & 166,324 & 8.4 & $79,952.0$ & $121,656.5$ & 52.2 \\
\hline D11 & 0.8302 & $2,293,984$ & $3,454,735$ & 50.6 & 157,570 & 189,787 & 20.4 & $105,146.0$ & $141,073.0$ & 34.2 \\
\hline D12 & 1 & $22,408,068$ & $22,408,068$ & 0.0 & 201,342 & 201,342 & 0.0 & $31,618.0$ & $31,618.0$ & 0.0 \\
\hline D13 & 0.5883 & $2,425,967$ & $7,914,977$ & 226.3 & 271,542 & 461,607 & 70.0 & $129,898.0$ & $341,976.5$ & 163.3 \\
\hline
\end{tabular}

\subsubsection{BCC-O Model}

The analysis of CCR-O model shows that D02, D03, D04, D07 and D12 are efficient, and other remaining 8 DMUs are inefficient. Then, we applied the BCC-O model to analyze whether the causes of 8 inefficient DMUs were due to pure technical factors or scale factors.

As shown in Table 6, which is the analysis of the BCC-O model, there are 7 DMUs, including, D02, D03, D04, D06, D07, D10 and D12 whose efficiency score is ' 1 '. The remaining 6 DMUs are found to be less efficient than these.

The average of efficiency score is 0.8699 and has a maximum score of 1 and minimum score of 0.3587 and standard deviation of 0.2093 . The average score of BCC-O is higher than CCR-O of 0.8349 .

Reference count for D02 is 4 times, 4 times for D03, 4 times for D04, once for D06, five times for D07, 3 times for D10 and 3 times for D12. Reference count of D07 is relatively high.

Reference count is referred to as the number used for different evaluations of DMU analysis, which implies that the higher the value is, the more often it is used for the other evaluations of DMU analysis [7].

To give an example of the relationship between DMUs that are evaluated as inefficient and the reference set, for improved efficiency of D01, the reference of D02, D03, D07 and D12 is necessary. The efficiency of D01 is $35.87 \%$ compared to $100 \%$ for the other four. Therefore, among the efficient DMUs, D03 should be a target of benchmarking as it has the highest weighted value. Other inefficient DMUs should apply the same methodology. 
Table 6. Summary of Outcomes for BCC-O Model

\begin{tabular}{c|c|c||c|c|c|c|c|c|c|c||c}
\hline DMU & Score & \multicolumn{1}{|c||}{ Rank } & \multicolumn{7}{|c|}{ Reference(Lambda) } & $\begin{array}{c}\text { \# of } \\
\text { reference }\end{array}$ \\
\hline \hline D01 & 0.3587 & 13 & D02 & 0.083 & D03 & 0.651 & D07 & 0.224 & D12 & 0.042 & 0 \\
\hline D02 & 1 & 1 & D02 & 1 & & & & & & & 4 \\
\hline D03 & 1 & 1 & D03 & 1 & & & & & & & 4 \\
\hline D04 & 1 & 1 & D04 & 1 & & & & & & & 4 \\
\hline D05 & 0.6819 & 11 & D03 & 0.301 & D04 & 0.655 & D07 & 0.044 & & & 0 \\
\hline D06 & 1 & 1 & D06 & 1 & & & & & & & 1 \\
\hline D07 & 1 & 1 & D07 & 1 & & & & & & & 5 \\
\hline D08 & 0.6113 & 12 & D04 & 0.994 & D12 & 0.006 & & & & & 0 \\
\hline D09 & 0.9581 & 9 & D03 & 0.132 & D04 & 0.092 & D07 & 0.775 & & & 0 \\
\hline D10 & 1 & 1 & D10 & 1 & & & & & & & 3 \\
\hline D11 & 0.966 & 8 & D02 & 0.141 & D07 & 0.519 & D10 & 0.34 & & & 0 \\
\hline D12 & 1 & 1 & D12 & 1 & & & & & & & 3 \\
\hline D13 & 0.7069 & 10 & D02 & 0.524 & D10 & 0.476 & & & & & 0 \\
\hline
\end{tabular}

In order to improve the inefficient DMU, projection obtained by comparing with the effective DMU is shown in Table 7 and Table 8.

DEA calculates a target value in order to improve inefficient DMUs by comparing with efficient DMUs.

Therefore, in order for D01 to be an efficient DMU, assets and liabilities (input factors) remains the constant while output factors for example, sales and operating profit each has to be increased by $179 \%(1,999,893$ hundred million won and 79,167 hundred million won, respectively) and net profit also should increase 3,572\% (52,113 hundred million won).

Table 7. Projection of BCC-O Model's Input Factors

\begin{tabular}{|c|c|c|c|c|c|c|c|}
\hline \multirow[b]{2}{*}{ DMU } & \multirow[b]{2}{*}{ Score } & \multicolumn{3}{|c|}{ Asset } & \multicolumn{3}{|c|}{ Capital } \\
\hline & & Data & Projection & $\begin{array}{l}\text { Diff. } \\
(\%)\end{array}$ & Data & Projection & $\begin{array}{c}\text { Diff. } \\
(\%)\end{array}$ \\
\hline D01 & 0.3587 & 570,438 & 570,438 & 0 & 508,862 & 508,862 & 0 \\
\hline D02 & 1 & $4,214,025$ & $4,214,025$ & 0 & $1,332,021$ & $1,332,021$ & 0 \\
\hline D03 & 1 & 93,668 & 93,668 & 0 & 59,455 & 59,455 & 0 \\
\hline D04 & 1 & 13,665 & 13,665 & 0 & 31,519 & 31,519 & 0 \\
\hline D05 & 0.6819 & 47,353 & 47,353 & 0 & 59,490 & 59,490 & 0 \\
\hline D06 & 1 & 28,666 & 28,666 & 0 & 8,131 & 8,131 & 0 \\
\hline D07 & 1 & 232,179 & 232,179 & 0 & 475,507 & 475,507 & 0 \\
\hline D08 & 0.6113 & 28,625 & 28,625 & 0 & 119,814 & 67,088 & -44 \\
\hline D09 & 0.9581 & 193,646 & 193,646 & 0 & 379,386 & 379,386 & 0 \\
\hline D10 & 1 & 824,990 & 824,990 & 0 & $1,411,102$ & $1,411,102$ & 0 \\
\hline D11 & 0.966 & 993,461 & 993,461 & 0 & $1,300,895$ & 914,207 & -30 \\
\hline D12 & 1 & $2,518,243$ & $2,518,243$ & 0 & $5,986,466$ & $5,986,466$ & 0 \\
\hline D13 & 0.7069 & $2,602,367$ & $2,602,367$ & 0 & $2,704,672$ & $1,369,642$ & -49 \\
\hline
\end{tabular}




\section{Table 8. Projection of BCC-O Model's Output Factors}

\begin{tabular}{|c|c|c|c|c|c|c|c|c|c|c|}
\hline \multirow[b]{2}{*}{ DMU } & \multirow[b]{2}{*}{ Score } & \multicolumn{3}{|c|}{ Sales } & \multicolumn{3}{|c|}{ Operation profit } & \multicolumn{3}{|c|}{ Net profit } \\
\hline & & Data & Projection & $\begin{array}{c}\text { Diff. } \\
(\%)\end{array}$ & Data & Projection & $\begin{array}{c}\text { Diff. } \\
(\%)\end{array}$ & Data & Projection & $\begin{array}{c}\text { Diff. } \\
(\%) \\
\end{array}$ \\
\hline D01 & 0.3587 & 717,410 & $1,999,893$ & 179 & 28,399 & 79,167 & 179 & 1,419 & 52,113 & 3,572 \\
\hline D02 & 1 & $7,897,748$ & $7,897,748$ & 0 & 593,419 & 593,419 & 0 & 434,273 & 434,273 & 0 \\
\hline D03 & 1 & 235,040 & 235,040 & 0 & 14,361 & 14,361 & 0 & 8,765 & 8,765 & 0 \\
\hline D04 & 1 & 99,116 & 99,116 & 0 & 2,034 & 2,034 & 0 & 1,807 & 1,807 & 0 \\
\hline D05 & 0.6819 & 114,130 & 183,407 & 61 & 5,447 & 7,988 & 47 & 3,305 & 5,569 & 69 \\
\hline D06 & 1 & 35,666 & 35,666 & 0 & 2,635 & 2,635 & 0 & 2,628 & 2,628 & 0 \\
\hline D07 & 1 & $1,084,167$ & $1,084,167$ & 0 & 53,023 & 53,023 & 0 & 39,693 & 39,693 & 0 \\
\hline D08 & 0.6113 & 142,056 & 232,369 & 64 & $-6,293$ & $-7,079$ & 12 & $-9,297$ & $-13,230$ & 42 \\
\hline D09 & 0.9581 & 421,262 & 880,701 & 109 & 41,381 & 43,192 & 4 & 26,614 & 32,097 & 21 \\
\hline D10 & 1 & $3,317,560$ & $3,317,562$ & 0 & 153,372 & 153,372 & 0 & 79,952 & 79,952 & 0 \\
\hline D11 & 0.966 & $2,293,984$ & $2,801,601$ & 22 & 157,570 & 163,110 & 4 & 105,146 & 108,843 & 4 \\
\hline D12 & 1 & $22,408,068$ & $22,408,068$ & 0 & 201,342 & 201,342 & 0 & 31,618 & 31,618 & 0 \\
\hline D13 & 0.7069 & $2,425,967$ & $5,719,658$ & 136 & 271,542 & 384,155 & 41 & 129,898 & 265,775 & 105 \\
\hline
\end{tabular}

\subsubsection{Analysis of Efficiency of Scale and Return to Scale}

In this study, the Scale Efficiency (SE) approach, which is based on the CCR and BCC scores, is applied to measure the relative efficiency of DMUs by scale efficiency method[7].

Let the CCR and BCC scores of a DMU be $\theta_{C C R}^{*}$ and $\theta_{B C C}^{*}$ respectively, and the SE is defined by the formula (4). SE is less than and equal to the maximum efficiency score 1.

$$
\mathrm{SE}=\frac{\theta_{C C R}^{*}}{\theta_{B C C}^{*}}
$$

And the SE, technical efficiency value divided by the value of pure technical efficiency is found to be $95.97 \%$. This can be seen as that the cause of inefficiency of business may be due to rather PTE than TE.

There are three types of Return to Scale (RTS). CRS (Constant Returns to Scale) is when the CCR score and BCC score values are equal or $\sum_{j=1}^{n} \lambda_{j}=1$. IRS(Increasing Returns to Scale) states if the CCR score and BCC score are not equal and $\sum_{j=1}^{n} \lambda_{j}<1$. And DRS (Decreasing Returns to Scale) is when CCR score and BCC score not equal and $\sum_{j=1}^{n} \lambda_{j}>1$.

If an inefficient DMU is in the IRS state, the marginal revenue increases with the increase in input factor. That is, it is possible to improve the efficiency through an increase in scale. If an inefficient DMU is in the DRS state, the marginal revenue decreases with increase in the input factors. Thus, improvement in efficiency can be achieved through a reduction in scale [7]. 
Table 9. Summary of SE and RTS

\begin{tabular}{c|c|c|c|c}
\hline DMU & CCR Score & BCC Score & SE & RTS \\
\hline \hline D01 & 0.3574 & 0.3587 & 0.996375802 & DRS \\
\hline D02 & 1 & 1 & 1 & CRS \\
\hline D03 & 1 & 1 & 1 & CRS \\
\hline D04 & 1 & 1 & 1 & CRS \\
\hline D05 & 0.6524 & 0.6819 & 0.956738525 & CRS \\
\hline D06 & 0.9914 & 1 & 0.9914 & IRS \\
\hline D07 & 1 & 1 & 1 & CRS \\
\hline D08 & 0.5577 & 0.6113 & 0.912318011 & CRS \\
\hline D09 & 0.9545 & 0.9581 & 0.996242563 & CRS \\
\hline D10 & 0.9221 & 1 & 0.9221 & DRS \\
\hline D11 & 0.8302 & 0.966 & 0.85942029 & DRS \\
\hline D12 & 1 & 1 & 1 & CRS \\
\hline D13 & 0.5883 & 0.7069 & 0.832225209 & DRS \\
\hline Average & 0.8349 & 0.8699 & 0.9597 & \\
\hline
\end{tabular}

\subsubsection{Analysis of Super Efficiency}

As the result of CCR-O model analysis, 5 DMUs (D02, D03, D04, D07, D12) were shown to be efficient, and BCC-O model analysis demonstrates that, 7 DMUs (D02, D03, D04, D06, D07, D10, D12) are efficient.

The re-evaluation of both 5 DMUs (from CCR-O model) and 7 DMUs (from BCC-O model) with same efficiency is implemented by Super Efficiency model is shown in the Table 10. The order of efficiency ranking in the CCR-O model is D02, D07, D12, D04 and D03 and in the BCC-O models D02, D12, D07, D10, D03, D04 and D06.

Table 10. Outcome of Super Efficiency

\begin{tabular}{c||c|c||c|c}
\hline \multicolumn{1}{c||}{ Rank } & \multicolumn{2}{c||}{ CCR } & \multicolumn{2}{c}{ BCC } \\
\cline { 2 - 5 } & DMU & Score & DMU & Score \\
\hline \hline 1 & D02 & 1.443 & D02 & 4.109 \\
\hline 2 & D07 & 1.261 & D12 & 3.997 \\
\hline 3 & D12 & 1.227 & D07 & 1.451 \\
\hline 4 & D04 & 1.168 & D10 & 1.202 \\
\hline 5 & D03 & 1.006 & D03 & 1.066 \\
\hline 6 & D06 & 0.991 & D04 & 1.000 \\
\hline 7 & D09 & 0.955 & D06 & 1.000 \\
\hline 8 & D10 & 0.923 & D11 & 0.966 \\
\hline 9 & D11 & 0.830 & D09 & 0.958 \\
\hline 10 & D05 & 0.652 & D13 & 0.707 \\
\hline 11 & D13 & 0.588 & D05 & 0.682 \\
\hline 12 & D08 & 0.558 & D08 & 0.611 \\
\hline 13 & D01 & 0.357 & D01 & 0.359 \\
\hline
\end{tabular}




\section{Conclusions}

The objective of this study was to enhance the ability to increase competitive advantage of logistics-IT companies that are affected by a downturn in logistics industry, and both domestic and global economy. We have evaluated the if logistics-IT companies are managed efficiently, and identified their inefficiency to promote competitive advantage by producing a goal.

The subject of the study includes IT companies that are listed in domestic stock market with high sales and they are names as Logistics-IT company and 13 companies met the criteria. We have measured efficiency of these companies and utilized DEA model for analysis of inefficient companies.

For analysis, we have selected assets and liabilities as input factors and sales, operating profit and net profit as output factors.

The application of CCR-O model enabled measurement of TE by investigating into how much output factor could be increased with input factor remaining at the same level. BCC-O model was used to measure and analyze PTE and SE.

The results show that 5 companies were efficient in the CCR-O model, and 7 companies were relatively efficient in the BCC-O model.

The result of applying the CCR-O model shows that the average value of technical efficiency of business is $83.49 \%$. Measured by the BCC-O model, pure technical efficiency (PTE) is $86.99 \%$.

And SE calculated as technical efficiency value divided by the value of pure technical efficiency is found to be $95.97 \%$. This can be seen as the cause of inefficiency of business may be due to PTE rather than TE.

This means that, compared to inputs that are invested, the level of outputs are low implying that technical inefficiency has occurred.

We performed the rank analysis by applying the super efficiency method to distinguish between the DMUs with the same efficiency value [7].

Implications of the present findings are as follows.

First, the DEA model implemented to evaluate efficiency score indicates relative efficiency among companies. It can be used to establish a strategy to improve efficiency of inefficient companies and proposed a method to manage resources on hand most efficiently.

In addition, we have suggested if the cause of inefficiency was due to scale inefficiency or pure technical inefficiency by using CCR and BCC models. Majority of the cases demonstrated that inefficiency was due to PTE. Therefore, inefficiency should be handled with retrenchment of expenditure etc.

\section{Acknowledgement}

This research was supported by Seokyeong University in 2015 .

\section{References}

[1] N. Adler, L. Friedman, Z. Sinuany-Stern, "Review of Ranking Methods in the Data Envelopment Analysis Context", European Journal of Operation Research, vol. 140, (2002), pp.249-265.

[2] W.R. Bitman and N. Sharif, "A Conceptual Framework for Ranking R\&D Projects", IEEE Transactions on Engineering Management, vol. 55, no. 2, (2008), pp.267-278.

[3] A. Charnes, W.W. Cooper and E. Rhodes, "Measuring the Efficiency Government-Sponsored R\&D Projects: A Three Stage Approach," Evaluation and Program Planning, vol. 32, no. 2, (2009), pp.178186.

[4] A. Charnes, W.W. Cooper and E. Rhodes, "Measuring the Efficiency of Decision Making Units", European Journal of Operation Research, vol.2, no.6, (1978), pp.429-444.

[5] W.W. Cooper, L.M. Seiford, and K. Tone, Data Envelopment Analysis: A Comprehensive Text with Models, Applications, References and DEA-Solver Software, Second Edition, Springer, New York, (2006). 
[6] J.A. Fitzsimmons, M.J. Fitzsimmons, Service management for Competitive Advantage, McGrow-Hill Inc., (1994).

[7] H.W. Goh, "The Efficiency Comparative Evaluation of IT Service Companies using the Data Envelopment Analysis Approach Focus on KOSDAQ(Korea Securities Dealers Automated Quotations)", International Journal of Software Engineering and its Applications, vol. 9, no. 5, (2015), pp.205-218.

[8] H.W. Goh, "A Study on Evaluation Management Productivity for Logistics-IT Corporations," Proceedings International Workshop Mechanical Engineering 2016, Advanced Science and Technology Letters (ASTL), Vol. 133(Information Technology and Computer Science), SERSC, (2016), pp. 201206.

[9] S. Lee, G. Mogi, M. Koike, K.S. Hui and J. Kim, "DEA scale efficiency approach on measuring the relative efficiency values of energy technologies in the sector of mid-term strategic energy technology development plan," KORMS/KIIE Proceeding, (2009), pp.22-23.

[10] JaeHyun Kim, "Measuring and Evaluation of Productivity for Logistics-IT Corporations", Asia-Pacific Proceedings of Applied Science and Engineering for Better Human Life, vol. 10, (2016), pp. 121-124

[11] C.Y. Lin, G. E. Okudan, "An Exploration on the Use of Data Envelopment Analysis for Product Line Selection," Industrial Engineering \& Management Systems, vol.8, no. 1, (2009), pp. 47-53.

[12] J.C. Paradi, S. Smith and C. Schaffnit-Chatterjee, "Knowledge Worker Performance Analysis Using DEA: An Application to Engineering esigh Team at Bell Canada," IEEE Transactions on Engineering Management, vol.49, no. 1, (2002), pp. 161-171.

[13] J. M. Wagner, D. G. Shimshak, "Stepwise Selection of Variables in Data Envelopment Analysis: Procedure and Managerial Perspectives," European Journal of Operational Research, vol. 180, (2007), pp. 57-67.

\section{Author}

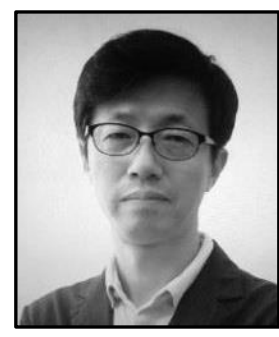

JaeHyun Kim, he received the B.S. degree from the Dept. of Mathematics, Hanyang University, Seoul, Korea, in 1986, and M.S. and Ph.D. degrees from Dept. of Statistics, Dongguk University, Seoul, Korea in 1989 and 1996, respectively. He was a Chairman of Dept. of Internet Information 2002-2007. Currently, he is a member of the Korean Data \& Information Science Society and a Professor of Dept. of Computer Engineering, Seokyeong University, Seoul, Korea. His research areas include mobile programming, cloud system and data analysis. 
International Journal of Grid and Distributed Computing Vol. 10, No. 10 (2017) 